\title{
José Martí: antecedentes de una ecología popular latinoamericana
}

\author{
José Martí: background of a Latin American popular ecology \\ José Martí: antedecentes de uma ecologia popular latinoamericana
}

DOI: http://dx.doi.org/10.21803\%2Fpenamer.11.21.527

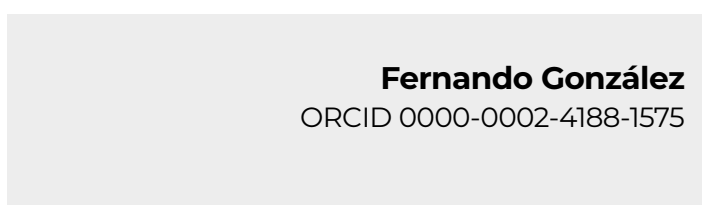

\section{Resumen}

La Ecología Política creció en Latinoamérica desde propuestas como los "derechos de la naturaleza", el "buen vivir" o el "ecosocialismo". Sin embargo, la mayoría de la producción en este campo muestra escasa vinculación con el pensamiento latinoamericano del siglo XIX. Para aportar a completar esta vacancia, se propone recuperar las principales dimensiones del pensamiento de José Martí en dicha área del conocimiento.

En primer lugar, caracterizar el contexto en que se desarrolla el pensamiento martiano. Luego repasar las influencias con las que conformó este aspecto de su pensamiento. Así, llegar a lo que se puede denominar el "pensamiento ambiental martiano", comenzando por su concepción de la relación sociedad-naturaleza y continuando por las implicancias políticas y económicas de sus planteos.

El trabajo fue realizado a través de fuentes secundarias, tanto de la obra del autor como de otros trabajos que profundizan sobre su pensamiento. Los resultados constatan la presencia de una crítica temprana a una economía basada en estructuras monoproductivas y basadas en el consumismo.

PALABRAS CLAVES: Martí, pensamiento ambiental, naturaleza, ecología política.

\begin{abstract}
Political Ecology grew in Latin America from proposals such as "rights of nature", "good living" or "ecosocialism". However, the majority of production in this field shows limited connection with the Latin American thought of the 19th century. To contribute to complete this vacancy, it is propose to recover the main dimensions of José Martís thinking in this area of knowledge.

First, characterize the context in which Marti's thought develops. Then review the influences with which he conformed this aspect of his thought. Thus, arrive to what you can call the "martian environmental though", beginning with its conception of the society-nature relationship and continuing with the political and economic implications of its proposals.

The work was done through secondary sources, both the work of the author and other works that deepen their thinking. The results confirm the presence of an early criticism in an economy based on single-product structures and based on consumerism.
\end{abstract}

\section{¿Cómo citar este artículo?}

González, G. (2018). José Martí: antecedentes de una ecología popular latinoamericana. Pensamiento Americano, 11(21), 96-109

KEYWORDS: Martí, environmental thought, nature, political ecology. 


\section{Resumo}

A Ecologia Política cresceu na América Latina desde propostas como os "direitos da natureza", o "bom viver" ou o "ecosocialismo". Entretanto, a maioria da produção neste campo mostra escassa vinculação com o pensamento latino-americano do século XIX. Para completar essa lacuna, nos propomos recuperar as principais dimensões do pensamento de José Martí nesta referida área de conhecimento.

Em primeiro lugar, caracterizamos o contexto em que se desenvolve o pensamento martiano. Logo, repassaremos as influências com as que se conformou esse aspecto de seu pensamento. Assim, chegaremos ao que podemos denominar o "pensamento ambiental martiano", começando pela sua concepção da relação sociedade-natureza e continuando pelas implicações políticas e econômicas de suas propostas.

O trabalho foi realizado através de fontes secundárias, tanto da obra do autor como de outros trabalhos que aprofundaram seu pensamento. Os resultados constatam a presencia de uma crítica a uma economia baseada nas estruturas mono-produtivas e baseadas no consumismo.

PALAVRAS CHAVE: Martí, pensamento ambiental, natureza, ecologia política.V

\section{Perfil}

Doctor en Geografía por la UBA.

Becario Postdoctoral del Consejo Nacional de Investigaciones Científicas

y Técnicas (CONICET). Miembro del Programa de Estudios Regionales y Territoriales (PERT) con sede en el Instituto de Geografía de la UBA. gonzalezjosefer@gmail.com

\section{Fernando González}

Licenciado en Sociología por la Universidad de Buenos Aires (UBA). 


\section{Introducción}

Erach I pensamiento ambiental latinoamericano ha crecido cualitativa y cuantitativamente en las últimas décadas. Esta evolución se dio al ritmo de los permanentes conflictos que el desarrollo capitalista produce en la relación con su propia base natural. Diversos autores han sido parte de este crecimiento (Enrique Leff, Gian Carlo Delgado Ramos, Guillermo Foladori, solo por nombrar algunos). También fueron diferentes perspectivas las que han fortalecido la importancia científica y política de esta área del pensamiento, ya sea desde el marxismo latinoamericano (Héctor Alimonda), desde los planteos descolonizadores (Alberto Acosta), desde la teología de la liberación (con pensadores como Leonardo Boff).

No ha sido solamente el pensamiento ambiental lo que ha cobrado nuevo impulso sino también ha crecido la intervención estatal en este terreno. Las discusiones de la última década sobre "los derechos de la naturaleza", "el buen vivir" (o vivir bien), que se han plasmado en los textos constitucionales Ecuador y Bolivia, dan cuenta de ello. Estas propuestas y visiones, al asentarse mayormente sobre aspectos vinculados a las cosmovisiones de los pueblos originarios del continente, no muestran vinculación con otros pensamientos anticoloniales, como el de muchos revolucionarios independentistas del siglo XIX. Por ello, es nuestro objetivo recuperar algunas de las dimensiones del pensamiento ambiental de José Martí. Se cree que esta tarea es necesaria, para reforzar la conformación de una ecología popular latinoamericana, que recupere diversas tradiciones del pensamiento latinoamericano (Herrera, 2010).

Para comprender el pensamiento martiano será importante comenzar describiendo el contexto en que el mismo se desarrolló. En segundo término, recorrer brevemente las influencias que Martí recibió para formar su pensamiento en esta área, vinculadas principalmente a su actividad revolucionaria y a su profesión. Luego ahondar en lo que se puede denominar propiamente el "pensamiento ambiental martiano", comenzando por su concepción de la naturaleza y siguiendo por su entendimiento sobre la relación entre ser humano y aquella. Posteriormente, repasar las implicancias políticas y económicas de estos planteamientos. Finalmente, con el fin de no caer en una recuperación meramente filosófica, ver cómo han sido recuperados algunos elementos de estos elementos en la política ambiental cubana de los últimos tiempos.

\section{Martí y su época}

Para comprender la obra de cualquier autor es preciso conocer el momento histórico en el que escribió, conocer los sucesos políticos, económicos y sociales que se sucedían y con ello el "clima de época" intelectual del que formaban parte. En el caso de José Martín, se refiere a la segunda mitad del siglo XIX, que transcurrió entre su infancia en Cuba, diversos exilios (en España, México, Estados Unidos y otros países vecinos a su país natal) y su regreso para encabezar la lucha por la independencia, donde encontró la muerte.

Nacido en 1853 en la ciudad de La Habana, Martí vivió toda su vida sacudido por los diferentes intentos de emancipación de su país frente a la corona española. Su educación estuvo marcada por las ideas del maestro cubano Rafael María de Mendive, director de su escuela y uno de los revolucionarios que ya en 1869 organizaban actividades por la independencia de Cuba. Esta cercanía hizo que ya a sus 15 años Martí adhiera a las diferentes tentativas de emancipación frente a España.

Ese mismo año (1869) es detenido por una carta firmada por él y su amigo Fermín Valdez Domínguez y luego de ser enjuiciado y encar- 
celado, le ofrecen ser liberado, pero exiliado a España. Allí comienza su carrera de escritor. Textos como "El presidio político en Cuba" (1971), donde relata la opresión y los crímenes del colonialismo español en Cuba y luego "La República Española ante la Revolución Cubana", publicado como un folleto en el que intenta dialogar con los defensores de las ideas republicanas en España, para que apliquen los mismos criterios respecto a Cuba.

Durante ese primer exilio, el poeta cubano tuvo que transitar por diferentes países, conociendo sus culturas, sus corrientes literarias y científicas. Después de tres años en España (1871 - 1874), parte a Francia a fines de 1874, para ir a México (vía Liverpool y Nueva York), a donde llega en febrero del año siguiente. Sin embargo, su itinerario no se detiene ahí, ya que abandona México para ir hacia Guatemala y Venezuela, donde tampoco logra establecerse definitivamente. En 1879 ingresa nuevamente a Cuba de manera clandestina, pero es deportado (por segunda vez) a España. Como sostiene Roberto Fernández Retamar (2016, p. 27) "su existencia andariega no encontrará cierto reposo sino a partir de esta fecha, en que se fija en Nueva York", recién en 1881.

Desde ese lugar comenzará más arduamente su participación en el proceso revolucionario independentista que continuaba desarrollándose en la isla. Por ello, durante 1880 preside el "Comité Revolucionario Cubano de Nueva York", donde comienza a crecer su fama de líder y de orador entre los cubanos que buscan la independencia.

En dicha estancia se inmiscuirá también en las luchas obreras. Es por ello que en ocasión de la condena y asesinato de los "Mártires de Chicago" en 1986, escribió para el diario "La Nación" de Buenos Aires, describiendo detalladamente el clima social que se vivía en Norteamérica. Sostuvo en esa ocasión que "esta república, por el culto desmedido a la riqueza, ha caído, sin ninguna de las trabas de la tradición, en la desigualdad, injusticia y violencia de los países monárquicos" (Martí, 11, p. 335).

Su fama crecerá incluso a nivel internacional, y no solo como periodista o escritor. "Desde 1887 es cónsul de Uruguay en Nueva York. En 1888 es nombrado representante en los Estados Unidos y Canadá de la Asociación de la Prensa de Buenos Aires" (Fernández Retamar, 2016, p. 31). Y es por estas funciones que será el primero en condenar la política expansionista de Estados Unidos en 1888. Anticipando algunos de sus planteos vinculados a la política económica internacional, planteó en esa ocasión que:

Jamás hubo en América, de la independencia acá, asunto que requiera más sensatez, ni obligue a más vigilancia, ni pida examen más claro y minucioso que el convite que los Estados Unidos (...) determinados a extender sus dominios en América, hacen a las naciones americanas de menos poder (...). De la tiranía de España supo salvarse la América española; y ahora, (...) urge decir, porque es la verdad, que ha llegado para la América española la hora de declarar su segunda independencia (Martí, 6, p. 46).

En los años siguientes continuó denostando la política colonial que bajo diversos artilugios llevaba a cabo Estados Unidos. Un ejemplo de ello fue su participación como representante de Uruguay en la Conferencia Monetaria Internacional Americana en abril de 1891 donde rechaza la intención de crear una moneda común para todos los países de Latinoamérica y de Estados Unidos. El último paso que dio previo a su prometida acción de regresar a liberar a Cuba del dominio español fue la fundación del Partido Revolucionario Cubano (PRC), cuyas bases fundacionales "son aprobadas en Cayo Hueso, por representantes de la emigración de la localidad, de Tampa y de Nueva York" 
(Fernández Retamar, 2016, p. 36). Luego funda el periódico Patria que será el órgano de difusión del PRC y comienza a recorrer los centros de exiliados cubanos de toda la región para convocar a un nuevo intento revolucionario independentista. En 1895, ni bien comenzada la nueva batalla por la independencia, muere en combate.

Fue en todo este periodo en el que Martí formó su pensamiento, en el que el aspecto ambiental tiene un lugar importante, aunque aún no ha sido reconocido en su justa medida por quienes reivindicaron su vida y obra posteriormente. En todo su trayecto político e intelectual pudo entrar en contacto con diferentes corrientes de pensamiento que lo llevaron a conjugar una mirada propia de la naturaleza junto a su prédica anticolonialista. Se demostrará ahora cuales fueron las influencias que en ese derrotero lo llevaron a plantear aquella mirada.

\section{Influencias habaneras de la juventud y la ma- durez en el exilio}

Para analizar cuáles fueron los principales aportes de los que Martí se nutrió al desarrollar su original pensamiento, se partirá de las pocas investigaciones realizadas al respecto, generalmente procedentes de Cuba y/o países de Centroamérica. Una de las investigadoras cubanas que han ahondado en el pensamiento ambiental del prócer cubano es Mariana Serra García. Esta autora plantea que "la aprehensión martiana de las interrelaciones naturaleza-cultura transcurrió en un continuo proceso de integración y maduración conceptual". (Serra Garcia, 2007, p. 25).

Una primera etapa según la autora corresponde a su niñez, donde la propia vida habanera y las enseñanzas de su padre espiritual De Mendive lo pusieron en contacto con "las bellezas del mundo físico", que contrastaban con la moral proveniente de Europa y-como comprobaría luego- también de Estados Unidos. En esos tiempos pudo comenzar a formar ciertas visiones de la naturaleza de manera contemplativa, que luego reforzó con un mayor conocimiento desarrollado al respecto.

Se puede identificar en esta primera etapa tres elementos que contribuyeron a la conformación de este aspecto de su pensamiento: a) la literatura romántica y el tratamiento especial que esa corriente le daba a la naturaleza; b) diversos aportes científicos del estudio de la naturaleza; y c) una visión desde la filosofía y la ética a partir de quien fuera una de sus influencias cubanas más relevantes, José de la Luz y Caballero.

De la primera corriente se logra visualizar varias influencias, que luego irán tomando diferentes sentidos en el pensamiento martiano. Una de ellas es el pensamiento de Friedrich Schelling, de quien valoró su intención de asumir una identidad universalidad, pero sostuvo que ello lo llevaba a ver al hombre como análogo a lo que le rodea. Estudió detenidamente a este filósofo, y sostuvo que en su concepción "el yo es el universo mismo, y el universo mismo no es más que el yo" es por ello que sostiene que "confunde el sujeto y el objeto" (Martí, 5 , p. 226). Sin embargo, estas reflexiones fueron centrales en la forma de concebir la relación dual hombre-naturaleza. Sostenía que la idea de Schelling escondía una "dualidad inevitable que destruye la imposible identidad" entre sujeto y objeto (lbíd.).

Otra de esas influencias fue la de Karl Christian Krause. "Yo tuve gran placer cuando hallé en Krause esa filosofía intermedia, secreto de los dos extremos, que yo había pensado en llamar filosofía de relación" sostuvo en sus apuntes sobre filosofía (Martí, 19, p. 367). Este filósofo trasladaba el énfasis en las relaciones a diferentes esferas, entre ellas la naturaleza. Al definir su "Idea de la humanidad" sostenía que la 
misma no se basa "ni en el puro concepto de la naturaleza, ni en el mero agregado de ambos", ya que, aunque sean seres naturales, "queda sobre estos conceptos entera, propia y libre nuestra humanidad" (Krause, 2003, p. 20). En este sentido es que Krause pugnaba por aclarar lo más fielmente esas relaciones:

Cuanto más sean conocidas, mejor determinadas y más fielmente guardadas estas relaciones, tanto más plenamente realizará nuestra humanidad su destino en el tiempo y en esta tierra, tanto más conservará y mejorará sus relaciones con la naturaleza y el espíritu en el mundo, tanto más interior vivirá, y nosotros con ella (Ibíd., p. 10).

El otro ascendente del temprano pensamiento ambiental martiano está relacionado con los estudios científicos sobre la naturaleza que comenzaban a realizarse. Principalmente, en Cuba conoció la obra de Felipe Poey y Alloy, quien ya en 1836 escribió un Compendio de geografía de la Isla de Cuba, para luego editar Naturaleza y Civilización de la Grandiosa Isla de Cuba (1851). Ligado a esta racionalidad científica sobre la naturaleza, está presente el pensamiento económico que comenzaba a nacer y que reflexionaba sobre las actividades vinculadas con los recursos naturales. Una de estas influencias que se pueden reconstruir es la de Francisco de Frías y Jacott, un noble español nacido en La Habana, que heredó el título de "Conde de Pozos Dulces" y que entre sus obras se encuentra El reformismo agrario. En dicha obra, se encuentran las bases del pensamiento agrario de Martí que luego se profundizara. Sostenía este autor, que la agricultura cubana debía modernizarse (en un sentido distinto al de la actual agricultura). Entre sus propuestas está el abandono de los monocultivos, que ya era una práctica corriente. Recomendaba lo siguiente:

Acrecentar los productos disminuyendo la superficie cultivada; asociar diferentes cul- tivos para facilitar los unos por los otros; (...) conservar y activar la fertilidad de los terrenos por medio de los estiércoles, (...): he ahí, si no me engaño, lo que salvaría de la ruina $y$ de la miseria a una infinidad de propiedades por donde pasó la planta asoladora de nuestra rutina y de nuestras labranzas exclusivas (Frías y Jacott, 1937, p. 29).

Por último, el terreno de la ética, donde aparece la figura de José de la Luz y Caballero sobre quien Martí sostuvo que consagró su vida a "crear hombres rebeldes y cordiales que sacaran a tiempo la patria interrumpida de la nación que la ahoga y corrompe, y le bebe el alma y le clava los vuelos" (Martí, 2, p. 198). En Luz se repetía constantemente la discusión sobre la relación hombre-naturaleza. Este maestro, "percibió a la naturaleza como forjadora de la unidad y, al mismo tiempo de la diversidad del ser" (Serra García, 2007, p. 26). Se preguntaba si el hombre "¿No es quizá una pieza del gran todo, destinada a desempeñar un movimiento especial y parcial, pero, sin embargo, o por lo mismo, armonizador?" (De la Luz y Caballero, 2001, p. 173).

La segunda y definitiva etapa en la conformación del pensamiento ambiental martiano, según Serra García se patentizó a partir de 1882, cuando escribió su famoso prólogo a la segunda edición del Poema del Niagara (de Juan A. Pérez Bonalde). Sostenía en esta ocasión que "iel poema está en la naturaleza, madre de senos próvidos, esposa que jamás desama (...), maga que hace entender lo que no dice, consoladora que fortifica y embalsama!" (Martí, 7, p. 231). De esta época, son también los artículos dedicados a Charles Darwin, Ralph Emerson, Henry Torea y Henry George.

La obra de Henry Thoreau (padre del ambientalismo norteamericano), en especial Walden y Desobediencia Civil fue gratamente valorada por Martí y es por ello que lo llamaba "el 
trascendentalista, el místico, el filósofo natural de Massachussets" (Martí, 19, p. 237). El pensamiento de este autor era sumamente crítico de la naciente sociedad norteamericana, al punto de sostener, en su ensayo "Una vida sin principios" que el mundo actual solo era un lugar de negocios y que "si un hombre que ama los bosques camina por ellos durante la mitad de cada día, es visto como un vago; pero si dedica todo su día a la especulación, destrozando esos bosques (...), es estimado como industrioso y emprendedor" (Thoreau, 2008, p. 20-21).

La segunda clase de influencia que se reconoce corresponde a la difusión de los conocimientos de las ciencias naturales, de la mano de los trabajos de Darwin y Spencer. Del primero, sostuvo que su genio se despertó en el contacto con el suelo nuestro americano, que "nuestras maravillas lo avivaron (...) y lo sacudió y puso en pie nuestra naturaleza potentísima" (Martí, 15, p. 374). En cambio, ha sido crítico del segundo, a propósito de su desprecio por las clases bajas, a las que él les otorgaba un rol central en el desarrollo histórico de nuestro continente.

Por último, es de vital importancia para entender los vínculos entre el pensamiento ambiental y el económico en su obra, las influencias que recibió en su periodo de estancia en México, Guatemala y Venezuela a mediados de la década de 1870. Según Rafael Almanza en este periodo "Martí diseña todo un programa de progreso económico que, (...) intenta promover la capitalización autónoma" de los países latinoamericanos. Sin embargo "la proyección martiana choca una y otra vez con los procesos políticos que, en el último cuarto del siglo, transformaron definitivamente el capitalismo mercantil colonial en moderno capitalismo del subdesarrollo en Latinoamérica" (Almanza, 1990, p. 408). En esta misma época se entusiasmó con las concepciones progresistas de Henry George, quien en su obra Progreso y Pobre- za (1879), declaraba que la propiedad privada monopolista de la tierra anula el derecho de todo hombre al cultivo de la tierra, y solamente aumentan de manera injusta los ingresos de los terratenientes. "Solo Darwin en las ciencias naturales ha dejado en nuestros tiempos una huella comparable a la de George en la ciencia de la sociedad" (Martí, 19, p. 102), sostuvo Martí sobre su obra, que era adoptada por muchos sectores en Estados Unidos en ese momento.

Estos múltiples ascendentes en el ideario del prócer cubano conjugan antiimperialismo y crítica a las economías rentistas mono productoras, al mismo tiempo se entremezclan con una visión holística de la relación sociedad-naturaleza, que dan lugar a un interesante antecedente para reconstruir el pensamiento ambiental nuestro americano.

\section{Pensamiento ambiental martiano}

Para adentrarnos en los aspectos propiamente ambientales del ideario martiano, se iniciara precisando su concepción sobre "la naturaleza", a la que también en muchos textos nombraba como "la creación", pero en el marco de una óptica dual "creación-destrucción". También en ese sentido concibe al hombre y a la naturaleza dentro de una relación dialéctica "creación-transformación". Martí comienza tempranamente preguntándose:

¿Qué es la naturaleza? El pino agreste, el viejo roble, el bravo mar, los ríos que van al mar como a la Eternidad vamos los hombres: la naturaleza es el rayo de luz que penetra las nubes y se hace arco iris; el espíritu humano que se acerca y se eleva con las nubes del alma y se hace bienaventurado. Naturaleza es todo lo que existe, en toda forma, espíritus y cuerpos; corrientes esclavas en su cauce, raíces esclavas en la tierra; pies, esclavos como las raíces; almas menos esclavas que los pies. El misterioso mundo íntimo, el maravilloso mundo 
externo, cuanto es, deforme o luminoso $u$ obscuro, cercano o lejano, vasto o raquítico, licuoso o terroso, regular todo, medido todo menos el cielo y el alma de los hombres, es naturaleza (Martí, 19, p. 364).

En este mismo sentido, Martí postulaba (revelando su razonamiento relacional) que en la tierra "cada orden existente tiene relación con otro orden". Así, llega a sostener que "todo fortifica la creencia en la íntima dependencia y rigurosa analogía de las diversas creaciones de la naturaleza" (Martí, 23, p. 238). Por eso es por lo que, frente a diferentes episodios trágicos de la naturaleza, pudo realizar algunas apreciaciones sobre este carácter dual ("creación-destrucción"). Ejemplo de ello es su crónica sobre "El terremoto de Charleston" frente al cual dijo que "tragando hombres y arrebatando sus casas como arrebata hojas al viento, cumplió su ley de formación el suelo, con la majestad que conviene a los actos de creación y dolor de la naturaleza" (Martí, 11, p. 76). Algo similar sostuvo frente a las inundaciones que pudo visualizar en la región francesa de Carona al decir que la naturaleza también era la "mano ciega que despedaza lo que acaba de crear y fecundar, (...) aguas mensajeras de la muerte, estos ríos que se desbordan por la campiña amedrentada, (...) este rugido de la muerte que inconsciente, fatal, ciegamente devasta el campo fértil, el hogar amadísimo, el árbol que alimenta al hombre" (Martí, 3, p. 20). Esta autotransformación por medio de estos recurrentes episodios, son asumidas como "premisa indispensable para conservar el equilibrio" (Toledo, 2007, p. 23).

Aquí es donde cobra relevancia el rol del ser humano en la naturaleza, en una concepción que vale la pena recuperar en las actuales discusiones entre "biocentrismo" y "antropocentrismo". Martí consideraba claramente al ser humano como parte de la naturaleza a diferencia de muchos pensadores de la época. Sin embargo, no es un elemento más, sino que tiene su especificidad y una función concreta. Tampoco está situado por encima de los otros elementos, sino que es interdependiente y complementario con otros componentes de "la creación". Esta acepción martiana puede ser considerada como una síntesis humanista de la dualidad "hombre-naturaleza".

En sus escritos se logran apreciar muchas comprobaciones fehacientes de esta postura, donde incluso otorga al hombre el rol de "mejorador". Es en un texto de abril de 1878 titulado "Libros Nuevos" donde al analizar nuevas obras literarias sostiene que "el mundo no es una serie de actos, separados por catástrofes, sino un acto inmenso elaborado por una incesante obra de unión. Se hace viejo mejorando, pero natural y regularmente" (Martí, 15, p. 194). Por eso es que exclamaba y reclamaba una educación natural: "¡Benditas las manos que rectifican esas equivocaciones, y endulzan estos errores sombríos de la ciega madre creación!" (Martí, 6, p. 353). Esto no significaba, sin embargo, que el hombre debiera hacer y deshacer lo que quisiera de la naturaleza. En eso Martí es tajante cuando sostiene que "el hombre no es un soberbio ser central, individuo de especie única, a cuyo alrededor giran los seres del cielo y de la tierra, animales y astros; sino la cabeza conocida de un gran orden zoológico" (Martí, 5, p. 194). Y esto es lo que diferencia su humanismo del antropocentrismo positivista de la época. Y es en esa misma ocasión que sentencia: "Han muerto la teoría de las catástrofes, concepción hueca de Cuvier, y la teoría antropocéntrica, concepción presuntuosa de la sistemática escuela espiritualista" (Ibid.).

En síntesis, Martí sostenía que el hombre era al mismo tiempo que hijo de la naturaleza, un co-creador de esta. Afirmaba que "el arte no es más que la naturaleza creada por el hombre" sostenía que, dada su propia condición de ser natural, el ser humano debía subsistir y para 
ello modificar la naturaleza para que "siga su curso majestuoso, el cual el hombre, en vez de mejorar, interrumpe" (Martí, 21, p. 163). Pero no es este un destino predefinido de la relación hombre-naturaleza, como mucha literatura conservacionista pretende mostrar. Más bien lo contrario. Esa relación se podría convertir en virtuosa por medio de la educación natural, ya que creía que "urge sustituir al conocimiento indirecto y estéril de los libros por el conocimiento directo y fecundo de la naturaleza" (Martí, 8, p. 291). Y es así que consideró que "la historia es solamente la narración del trabajo de ajuste y los combates entre la Naturaleza extrahumana y la Naturaleza humana", completando su comprensión dialéctica de la dualidad hombre-naturaleza (Martí, 8, p. 44).

\section{Economía y política como parte de su pen- samiento ambiental}

Una de las primeras apreciaciones son las relaciones que Martí establece entre economía y ambiente es su visión humanista del progreso económico. Influido por autores como Henry George, sostenía que no era el objetivo de las economías el mero crecimiento, alejándose de eso que hoy se conoce como valores crematísticos (que solo se preocupan por los ingresos monetarios, es decir ponen como único fin el ganar dinero). Es así que en un texto sobre la situación de Honduras (Honduras y los extranjeros) publicado en Patria en 1894 sostuvo que

La grandeza de los pueblos no está en su tamaño, ni en las formas múltiples de la comodidad material, que en todos los pueblos aparecen según la necesidad de ellas, y se acumulan en las naciones prósperas, más que por genio especial de raza alguna, por el cebo de la ganancia que hay en satisfacerlas. El pueblo más grande no es aquel en que una riqueza desigual y desenfrenada produce hombres crudos y sórdidos, y mujeres venales y egoístas (...). La prueba de cada civilización humana está en la especie de hombre y de mujer que en ella se produce (Martí, 8, p. 35).

En este sentido, como anteriormente se menciono, al mismo tiempo que fue un fuerte crítico de las situaciones coloniales de los países de Nuestramerica (como propondría llamar a los países del Sur), fue también crítico de las actividades económicas que esta situación colonial imponía. Esto quiere decir, que no se acaba el problema económico al solucionar el problema de la dominación colonial del sistema político.

Entre las múltiples críticas que Martí realizaba en torno a las economías latinoamericanas se puede encontrar una temprana llamada de atención a la instalación de las economías de enclaves, en especial vinculadas a las actividades extractivas. Así es que durante su estancia en México, publicó para la Revista Universal en julio de 1875 unas reflexiones sobre comercio e industria en las que afirmó: "nada pone la industria extractiva en el lugar de lo que arranca. La industria fabril crea y transforma, en cambio, de un modo siempre nuevo productos fijos y constantes, en los que se asienta el verdadero bienestar de una nación" (Martí, 6, p. 268).

Pero no es esta crítica un rechazo a la actividad minera en sí misma, sino una crítica al metabolismo en el que se encuentra inserto. Sostenía que "las minas no son hoy un alimento de la riqueza nacional" (Ibíd.), pero debido a los términos del intercambio comercial con los países centrales. En el caso mexicano (como en muchos otros) sucedía que lo obtenido por la explotación de esos recursos, era luego enviado fuera del país para el pago de los productos importados que se consumen en el país ${ }^{2}$.

Es por esta concepción que la economía postulada por Martí era contraria a una economía mono-productiva, más aún si esa producción se basa en los recursos agotables. Continuando ese pensamiento es que sostiene (develando al-

Pensamiento Americano Vol. 11 - No. 21 • Julio-Diciembre • Corporación Universitaria Americana • Barranquilla, Colombia • ISSN: 2027-2448 
gunos rasgos de su herencia fisiocrática) que la actividad que más riqueza puede generar es la agricultura, ya que es esta la "única fuente constante cierta y enteramente constante pura de la riqueza" (Martí, 8, p. 298). Es por eso que llega a sostener una postura que puede ser vista (solo inicialmente) como una aceptación de la división internacional del trabajo:

Más oro y plata que en nuestras minas tenemos en nuestras plantas textiles, en nuestra farmacopea vegetal $y$ en nuestras maderas tintóreas y aromáticas. (...) La caña de azúcar, hasta en el tallo del maíz, en la calabaza y en la papa está teniendo competidores: el café viene a barcadas de la India. Países industriales ni somos, ni en mucho tiempo podremos ser: necesitamos, pues, mejorar constantemente nuestros cultivos, ya que nuestra tierra está saturada de estas plantas, y con buena labor las producirá mejor que sus rivales: necesitamos crear cultivos y explotaciones nuevas (Martí, 8, p. 366).

No obstante, no era cualquier agricultura la que proponía. Sostuvo una crítica bastante radical para su época a las políticas agrarias que inducían a los monocultivos. En marzo de 1883, desde Nueva York escribió un texto sobre el "Tratado Comercial entre los Estados Unidos y México" donde ya sostuvo que "comete suicidio un pueblo que fía su subsistencia a un solo fruto" (Martí, 6, p. 270). En ese mismo año, en un texto titulado "Plátanos" sostuvo, que "Guatemala debiera ver con miedo este mal hábito de entregarse a un cultivo exclusivo" (Ibíd.) Uno de los motivos por los que sostiene que estos modelos económicos generan dependencia es la fuerte especulación que hay detrás de ellos. Sostuvo que "han venido a ser estos cultivos, con las grandes operaciones bursátiles que se basan en ellos, verdaderos juegos de azar, y como bombas mágicas, que ya son de oro, ya de jabón" (Martí, 7, p. 189). Y es por ello que sostiene la importancia de la diversidad agrícola y el estudio de la misma.

Pero esta agricultura debía ser realizada, según su propuesta, de una manera que logra emparentarse a lo que hoy se denomina "agroecología". Es también en esos textos de 1883, en particular en "Abonos", donde sostuvo la importancia de una práctica agrícola científica (que bajo su concepción de la ciencia y la educación debía aprender de los procesos naturales). Aprovechar las fuerzas naturales, es importante para Martí porque "quien abona bien su tierra, trabaja menos, tiene tierra para más tiempo, y gana más" (Martí, 8, p. 299). Pero sin embargo alertó que "no hay que creer que todo abono se recomienda es bueno, porque cada puñado de tierra tiene su constitución propia" (Ibíd.). De esta manera se deja de lado la idea de que hay prácticas agrícolas universales, o insumos que pueden ser utilizados indistintamente para cualquier cultivo. El estudio y la experimentación de los abonos es importante dado que "de abonar la tierra con ciertas substancias suelen venir males irreparables" (Ibíd.). Así como recomendó la utilización de sangre para unos cultivos, recomendaba los residuos de café para otros.

Profundamente ligado a la práctica agrícola, tenía también una avanzada visión acerca de la necesidad de conservar, mejorar y multiplicar los bosques. Los motivos eran variados, algunos económicos y otros ambientales: Decía Martí que si bien la plantación de árboles es cara, "cuando están crecidos dan frutos, resina, corteza y después madera y leña cuando se cortan, todo lo cual paga con exceso el sacrificio que se hizo para criarlos" (Martí, 8, p. 302).

2. En el mismo texto de la Revista Universal, martí afirmó que "su riqueza minera comenzará a ser útil al país, cuando pueda aplicarse en beneficio de él mismo, y no haya de llevarse fuera de la patria en pago de las más sencillas necesidades materiales y domésticas. (...) sus productos se exportan, en pago de los efectos de consumo que se importan a méxico y que, por su naturaleza y la actual constitución social, han menester renovación pronta y constante" (Martí, 6, p. 237). 
Pero en el balance de la actividad forestal, las externalidades positivas que Martí reconocía eran las más importantes. Sostenía que:

Las masas de árboles favorecen las lluvias, dan humedad al aire, evitan que la tomen de las plantas agrícolas y las agoten; sujetan las tierras y las aguas, evitan los hundimientos, los arrastres, las inundaciones y los torrentes; dan frescura al suelo y permiten así que crezcan buenos pastos; forman abrigos en las regiones meridionales para preservar los cereales del viento solano o levante, en el período crítico de la granazón; son, en una palabra, los árboles, además de un gran elemento de riqueza, los mejores amigos de la agricultura y de la ganadería (Ibíd.)

Estos efectos benéficos de la actividad forestal qque fueron también valorizados por otros independentistas latinoamericanos como Simón Bolívar y Manuel Belgrano), eran centrales para mantener la fertilidad de los suelos ${ }^{3}$. Defender los bosques, eran para Martí algo central, y es por eso que en un texto de septiembre de 1883 ("Congreso Forestal" en el periódico neoyorquino La América) sostiene que hay "una cuestión vital para la prosperidad de nuestras tierras, y el mantenimiento de nuestra riqueza agrícola (...): la conservación de los bosques, donde existen; el mejoramiento de ellos, donde existen mal; su creación, donde no existen" (Ibíd.). Martí realiza esta afirmación no desde una visión economicista, sino desde una visión puramente ambiental, ya que "comarca sin árboles, es pobre. Ciudad sin árboles, es malsana. Terreno sin árboles, llama poca lluvia y da frutos violentos" (Ibíd.). Por último, responsabiliza de su destrucción a "los especuladores, que no ven que la fortuna rápida que hoy acumulan criminalmente, y a expensas de la fortuna pública, arrebata a la nación una fuente de riqueza permanente" (Ibíd.).

Por último, es necesario ubicar todo este aspecto del pensamiento martiano cerca del núcleo de su propuesta política: la emancipación latinoamericana y el combate al colonialismo. Ya en 1876 al denunciar el colonialismo estadounidense en México sostenía que se hacía "sentir la mano de los especuladores que desean de una manera rápida, nuevo cuerpo donde ejercer su comercio y sus explotaciones" (Martí, 6, p. 187). Se refería al peso que tenían (y aún tienen) los Estados Unidos en la política económica de dicho país. Por estas denuncias, que cada vez tomaron fuerza en sus crónicas periodísticas, llegó a ser censurado en La Nación (Buenos Aires) y en La Opinión Nacional (Caracas) ${ }^{4}$.

En el marco de esas denuncias es que sostiene principalmente que la política económica de la nación norteamericana busca solamente especular con los altos precios de bienes que el proceso de colonización pondría a disposición de la potencia. Denuncia de esta manera un "desborde mercantil", que inundaría de producción excedente los "pueblos menores" (como lo llama en repetidas ocasiones). Es así que en ocasión de la "Conferencia Monetaria de las Repúblicas de América", en mayo de 1891 advierte a los pueblos americanos el riesgo económico de estas iniciativas norteamericanas. Sostiene que ya que los Estados Unidos "creen en la superioridad incontrastable de 'la raza anglosajona contra la raza latina' (...). ¿Pueden los Estados Unidos convidar a Hispanoamérica a una unión sincera y útil para Hispanoamérica? ¿Conviene a Hispanoamérica la unión política

3. Los bosques "hacían en otros tiempos fertilísimas y saludables regiones enteras, que hoy vuélvanse estériles e insalubres, y en otras donde la facilidad de los riegos en los ardientes veranos constituía una perenne fuente de riqueza, ya se ven disminuir y a veces secarse antiquísimos manantiales (...)" (Martí, 8, p. 302)

4. $\quad$ El director de La nación, en septiembre de 1882, le plantea al notificarle la censurado de parte de una crónica que "sin desconocer el fondo de verdad de sus apreciaciones y la sinceridad de su origen, hemos juzgado (...) extremadamente radical en la forma absoluta en las conclusiones (...) La parte suprimida de su carta (...), podía inducir en el error de creer que se abría una campaña de denuncia contra los Estados Unidos como cuerpo político, como entidad social, como centro económico" (Fernandez Retamar, 2016, p. 38).

Pensamiento Americano Vol. 11 - No. 21 • Julio-Diciembre • Corporación Universitaria Americana • Barranquilla, Colombia • ISSN: 2027-2448 . http://coruniamericana.edu.co/publicaciones/ojs/index.php/pensamientoamericano 
y económica con los Estados Unidos?" (Martí, 6, p. 160). Y es a razón de este evento, que sentencia que

El pueblo que compra manda. El pueblo que vende sirve. Hay que equilibrar el comercio, para asegurar la libertad. (...) El influjo excesivo de un país en el comercio de otro, se convierte en influjo político (...). Cuando un pueblo fuerte da de comer a otro, se hace servir de él. (...) El pueblo que quiera ser libre, sea libre en negocios. Distribuya sus negocios entre países igualmente fuertes (Ibíd.).

Aquí se puede comprender de una manera más integral la relación martiana entre la libertad de los países para elegir las actividades económicas que deciden emprender, y las relaciones económicas internacionales, que comenzaban a institucionalizarse. A ello se le puede agregar la función que Martí le otorga al "hombre natural", que es el sujeto que debe comandar el gobierno de los países nuevos, dejando de lado la herencia europea y la creciente influencia norteamericana de la época.

"El libro importado ha sido vencido en América por el hombre natural" (Ibíd.) sostuvo. Pero ¿quién es este sujeto social? María Fernanda Pampín, afirma que "el hombre natural no es un sujeto individual, sino que se postula como colectivo, un «nosotros», del que Martí puede plantearse como ejemplo para poder reflexionar sobre la sociedad futura y deseable para el pueblo cubano" (Pampín, 2009, p. 113). En diferentes pasajes de Nuestramerica los ha nombrado de diversas maneras: "el potro del llanero", "la sangre cuajada del indio", "el mestizo autóctono" frente al "criollo exótico". Son diferentes denominaciones de los sectores populares que pueblan la geografía del continente. Pero este sujeto, precisa además una "educación natural", ya que "no hay batalla entre la civilización y la barbarie, sino entre la falsa erudición y la naturaleza" (Martí, 6, p. 17).
Como consecuencia de este proceso de conformación y valorización de este sujeto colectivo es que nace el buen gobernante, ya que "surgen los estadistas naturales del estudio directo de la Naturaleza". Afirma Martí que con este aprendizaje es que "los economistas estudian la dificultad en sus orígenes", poniendo de relieve la importancia del sistema natural al pensar la economía. Y de esta manera, el gobernante natural gobierna puede conformar un sistema de ideas apropiada y situado en cada contexto. El buen gobernante "no es el que sabe cómo se gobierna el alemán o el francés, sino el que sabe con qué elementos está hecho su país". Para Martí un buen gobierno "no es más que el equilibrio de los elementos naturales del país" (Ibíd.).

\section{Martí se hace presente en la política am- biental cubana}

La retardada independencia de Cuba, producto la transición tutelada por Estados Unidos mediante la "Enmienda Platt" (vigente hasta 1934) y los sucesivos gobiernos favorables a los intereses norteamericanos hicieron que muchos de los planteos martianos en el terreno ambiental, pasaran a ser palabras muertas en los primeros años de la primera independencia cubana. Sin embargo, aunque la recuperación del pensamiento martiano fue más que importante en la conformación del proceso revolucionario cubano, su aspecto ambiental recién comienza a recuperarse en las últimas décadas.

Esta revalorización tiene en el mismo Fidel Castro uno de sus impulsores, que desde 1992 comienza a denunciar la relación entre capitalismo, colonialismo y consumo desmedido de los países centrales, con la posibilidad de que desaparezca la especie humana ${ }^{5}$ Que también denuncia la aparición de los "biocombustibles", mediante los cuales "el papel de los países periféricos es producir energía barata para los países ricos centrales, lo que representa una nueva fase de la colonización" (Castro, 2007, p. 
41). En los últimos tiempos de su vida, también ha mostrado una honda preocupación por la crisis climática, a la que consideraba el mayor desafío que enfrenta la humanidad, como se puede ver en el artículo titulado "La larga marcha hacia el abismo" (Castro, 2012).

Pero más allá de las opiniones vertidas por el líder de la revolución cubana, el ideario ambiental martiano tuvo su revalorización apropósito de la introducción del "Programa nacional de Agricultura urbana y suburbana" en 1997, con el que también se vieron revalorizadas las técnicas agroecológicas y la enseñanza de la agricultura en las escuelas (como proponía en su idea de educación natural). Y para la misma época, se plasmará en la ley ambiental cubana que "las acciones ambientales en Cuba se sustentan en las concepciones martianas acerca de las relaciones del hombre con la naturaleza y en las ricas tradiciones que asocian nuestra historia con una cultura de la naturaleza"6. Tampoco lo hace la Estrategia Nacional de Educación Ambiental, del mismo año, con la que se retoma el planteo de la educación natural martiana y que ha sido reactualizada para el periodo 2010-2015 (Ministerio de Ciencia Tecnología y Medio Ambiente de Cuba, 2010).

\section{Reflexiones finales}

Enrique Leff, uno de los autores más importantes de la última década en lo que refiere a las temáticas ambientales en Latinoamérica, sostiene que lo que se podría denominar "ecología política latinoamericana" se encuentra en su momento fundacional. Afirma que para situar este campo no hay que "delimitar su espacio, fijar sus fronteras y colocar membranas permeables con disciplinas adyacentes" (Leff, 2006, p. 21). Por lo tanto, tampoco implica que al estar en sus momentos iniciales, no reconozca antecedentes de importancia. Justamente "para construir las bases seminales que den identidad y soporte a este nuevo territorio; para pensarlo en su emergencia y en su trascendencia" (Ibíd.) es que se recupera el pensamiento ambiental de José Martí.

En él se puede visualizar una apropiada integración de elementos críticos del pensamiento moderno con la reivindicación de elementos preexistentes al pensamiento colonial, los que son propios del hombre natural. Ese mestizaje intelectual, propone una mirada distinta al mero dominio de la naturaleza, sin esencializar la relación hombre-naturaleza. Elementos como conservación y transformación de los elementos naturales aparecen en un equilibrio no tan usual para la época. Críticas a la dependencia que generan las economías extractivas, junto a un rechazo a los monocultivos estuvieron un primer lugar de su pensamiento económico, sentando un preciado antecedente para quienes hoy en día llevan adelante esas mismas denuncias.

Para concluir, los que trabajos como este -aunque parcial y limitado- demuestran que la ecología política no es un hecho arbitrario de nuestro momento histórico, sino que está enraizado en las más diversas tradiciones del pensamiento latinoamericano. De esta manera se abona a construir una ecología política latinoamericana, que no busque ser lo "nuevo", sino que realice un proceso dialéctico entre los elementos "viejos" que puedan ser reelaborados y alimentados en una nueva síntesis histórica.

5. "Una importante especie biológica está en riesgo de desaparecer por la rápida y progresiva liquidación de sus condiciones naturales de vida: el hombre (...) Es necesario señalar que las sociedades de consumo son las responsables fundamentales de la atroz destrucción del medio ambiente. (...) Con solo el 20 por ciento de la población mundial, ellas consumen las dos terceras partes de los metales y las tres cuartas partes de la energía que se produce en el mundo. Han envenenado los mares y ríos, han contaminado el aire, han debilitado y perforado la capa de ozono, han saturado la atmósfera de gases que alteran las condiciones climáticas con efectos catastróficos que ya empezamos a padecer" (Castro, 1992)

6. Ley nacional de Ambiente de Cuba (Ley n81/1997) 


\section{Referencias}

Almanza Alonso, R (1990). En torno al pensamiento económico de José Martí. La Habana, Cuba: Ed. Ciencias Sociales.

Castro, F. (12 de junio 1992). Discurso en la Conferencia de Naciones Unidas sobre Medio Ambiente y Desarrollo. Rio de Janeiro, Brasil. Recuperado de: http://www.cubadebate.cu/opinion/1992/06/12/ discurso-de-fidel-castro-en-conferencia-onusobre-medio-ambiente-y-desarrollo-1992/

Castro, F. (2007). Tanques Ilenos, estómagos vacíos. La amenaza de los agrocombustibles. Buenos Aires, Argentina: Ediciones Luxemburg.

Castro, F. (5 de enero 2012). La larga marcha hacia el abismo. Recuperado de: www.cubadebate.cu/ reflexiones-fidel/2012/01/05/la-marcha-hacia-elabismo/

De la Luz y Caballero, J. (2001). Obras. Aforismos (Volumen I). La Habana, Cuba: Ediciones Imagen Contemporánea.

Fernández Retamar, R. (2016). Martí en su (tercer) mundo. En Fernández Retamar, R. (2016) Pensamiento anticolonial de nuestra América (pp. 23-74). Buenos Aires, Argentina: CLACSO.

Frías y Jacott, F. (1937). El reformismo agrario. Recuperado de: https://issuu.com/scduag/docs/ ihe14025 (acceso en julio 2017)

Herrera, A. (2010). La obligatoriedad del Departamento de Gestión Ambiental Empresarial y su marco normativo en Colombia. Pensamiento Americano, 3(4), 45-49.

Krause, K. (2003). Ideal de humanidad para la vida. Recuperado de: http://biblioteca.org.ar/ libros/89759.pdf

Leff, E. (2006). La ecología política en América Latina. Un campo en construcción. En H. Alimonda (2006) Los tormentos de la materia. Aportes para una ecología política latinoamericana (pp. 21-39). Buenos Aires, Argentina: CLACSO.

Martí, J. (2001) Obras Completas, 26 volúmenes. La Habana, Cuba: Centro de Estudios Martianos CLACSO. Recuperado de: http://www.biblioteca. clacso.edu.ar/

Ministerio de Ciencia, Tecnología y Medio Ambiente (2010). Estrategia Nacional de Educación Ambiental 2010-2015. La Habana, Cuba.

Pampín, M. F. (2009). Los Diarios de Martí y el Hombre Natural. Temas $N^{\circ} 57$, pp. 105-114.

Serra García, M. (2007). La esperanza del mundo. La
Edad de Oro y la construcción de una ética y una cultura ambiental. La Habana, Cuba: Edición: Centro Félix Varela.

Thoreau, H. (2008). Desobediencia civil y otros textos. La Plata, Argentina: Ediciones Utopía Libertaria.

Toledo, J. (2007). La naturaleza en José Martí. La Habana, Cuba: Editorial Científico-Técnica. 